\title{
Assessment of Roughness of Fiber-reinforced Polymer Composite Wires and Other Coated Esthetic Archwires
}

\author{
Ramasamy Madasamy ${ }^{1}$, Ramachandra Prabhakar ${ }^{2}$, Thirunavukarasu Ramanadhan ${ }^{3}$, Saravanan Ramachandran ${ }^{4}$, \\ Rajvikram Natrajan ${ }^{5}$, Sowndarya Vasudevan ${ }^{6}$
}

\begin{abstract}
Aim and objective: The objective of this study was to assess the roughness of three coated archwires and fiber-reinforced polymer composite wires "as received" and post-deflection.

Materials and methods: The sample comprises 40 esthetic archwire segments $(n=10)$ with $0.018^{\prime \prime}$ size of epoxy-coated NiTi wire (G\&H), optiflex (Ormco), rhodium-coated NiTi wires (American Orthodontics), and fiber-reinforced polymer composite wires (Biomers) were analyzed. The specimen was evaluated for roughness "as received" and each wire was deflected up to at a crosshead speed of $2.5 \mathrm{~mm}$ per minute in a universal test machine (Instron, model 4501). The evaluation of final roughness was done after a deflection on a similar aspect of wire. The comparison of roughness among the different wire brands before and after deflection was evaluated using a one-way ANOVA test. The statistically significant difference in roughness among the two groups was analyzed by Tukey's honestly significant difference test (HSD).

Results: Fiber-reinforced polymer composite wires showed mild roughness than epoxy-coated NiTi wire which showed increased roughness. ANOVA shows statistical significance among wire "as received" and post-deflection. Epoxy-coated NiTi exhibited significantly increased roughness among other groups "as-received" and after deflection $(p=0.011)$.

Conclusion: The coating of the esthetic wire estimates the roughness of orthodontic wires, but it is determined by the coating method. The roughness is increased after a deflection in wires. Epoxy-coated wires showed significantly increased roughness in comparison with other esthetic archwires.

Clinical significance: The roughness of the surface influences friction, color stability, and deterioration properties. It stipulates the stability of color in archwires, effectiveness of guided tooth movement over the archwire, and biocompatibility.

Keywords: Coated archwires, Esthetic archwires, Fiber-reinforced polymer composite wires, Roughness.

World Journal of Dentistry (2021): 10.5005/jp-journals-10015-1802
\end{abstract}

\section{INTRODUCTION}

The visage of the appliance in orthodontics has become a major esthetic concern for the patients seeking orthodontic treatment. The esthetic quality of archwires is improved by a coating of polytetrafluoroethylene (PTFE), epoxy resin, and rhodium over the metallic archwire. ${ }^{1}$ Epoxy resin exhibits excellent adhesion, dimensional stability, and resistance to chemical agents. ${ }^{2}$ Optiflex wires are nonmetallic composed of clear optical fiber with a central core of silicon dioxide, cladding of silicon resin for moisture protection and a coating of nylon provides resistance to strain and increases strength. ${ }^{3}$

However, the durability of the esthetic coatings is not clinically evident as they tear over a period of time., ${ }^{2,4}$ To overcome the drawbacks of coated archwires, through composite technology of continuous fibers and polymer matrix by tube shrinkage technique, fiber-reinforced polymer composite archwires (FRPC) were introduced. ${ }^{5,6}$ The esthetic property is enhanced by the translucent nature of the polymer matrix and material flexibility. ${ }^{7-9}$

In orthodontic treatment, both fixed and removable appliances can cause periodontal problems and demineralization of enamel due to plaque accumulation. ${ }^{10}$ Accumulation of plaque is determined by the roughness of the surface of the archwire. Hence, the surface roughness has a major effect. ${ }^{11}$

The roughness of the surface influences friction, color stability, and deterioration properties. ${ }^{12,13}$ It stipulates the stability of color in archwires, effectiveness of guided tooth movement over the archwire, and biocompatibility. ${ }^{13-16}$
${ }^{1}$ Department of Orthodontics, Dr. MGR Educational Research Institute University, Chennai, Tamil Nadu, India

${ }^{2,4-6}$ Department of Orthodontics, Thai Moogambigai Dental College and Hospital, Chennai, Tamil Nadu, India

${ }^{3}$ Department of Orthodontics, Karpaga Vinayaga Institute of Dental Sciences, Chennai, Tamil Nadu, India

Corresponding Author: Sowndarya Vasudevan, Department of Orthodontics, Thai Moogambigai Dental College and Hospital, Chennai, Tamil Nadu, India, Phone: +91 9444642102, e-mail: dr.v.sowndarya@gmail.com

How to cite this article: Madasamy R, Prabhakar R, Ramanadhan T, et al. Assessment of Roughness of Fiber-reinforced Polymer Composite Wires and Other Coated Esthetic Archwires. World J Dent 2021;12(2):156-159.

Source of support: Nil

Conflict of interest: None

Researchers have elicited a direct relationship between the corrosion of archwires causing a release of ions in the oral environment and surface roughness. An increase in surface roughness increases the frictional force, as there are raised contact between archwire and bracket interface. ${ }^{15,17}$ The objective of this study was to assess the roughness of three coated archwires and fiber-reinforced polymer composite wires "as received" and postdeflection. 


\section{Materials and Methods}

The study was conducted in CIPET: School for Advanced Research in Polymers (SARP)-ARSTPS, Guindy, Chennai, Tamil Nadu, India. The sample comprises 40 esthetic archwire segments $(n=10)$ with 0.018 " size of epoxy-coated NiTi wire (G\&H), optiflex (Ormco), rhodium-coated NiTi wires (American Orthodontics), and fiberreinforced polymer composite wires (Biomers) were analyzed. Each sample wire was cut into $20 \mathrm{~mm}$ length with an orthodontic wire cutter and washed in distilled water to remove the surface impurities and blot dried.

Each archwire of two straightened sections of $20 \mathrm{~mm}$ in length was positioned in a metal block with maxillary central incisor metal brackets ( $3 \mathrm{~m}$ Unitek Gemini Metal Twin Brackets) stabilized with cyanoacrylate adhesive (Quickfix), with a distance between the two brackets of $15 \mathrm{~mm}$. The brackets were secured with the wire by elastomeric modules (Ormco). The archwire was oriented at a constant speed of $0.5 \mathrm{~mm} / \mathrm{second}$ to the surface rugosimeter stylus needle measuring $5-\mu \mathrm{m}$ in diameter. The average of three readings for each orthodontic treatment was recorded for the surface roughness. The specimen was evaluated for roughness "as received" and each wire was deflected up to at a crosshead speed of $2.5 \mathrm{~mm}$ per minute in a universal test machine (Instron, model 4501). The evaluation of final roughness was done after a deflection on a similar aspect of wire.

The data obtained were entered into the computer database. The response of frequencies was calculated and examined in the statistical Software Package of Social Sciences (SPSS) version 22.0 version. The comparison of roughness among the different wire brands before and after deflection was evaluated using a one-way ANOVA test. A statistically significant difference in roughness among the two groups was analyzed by Tukey's honestly significant difference test (HSD). The significance levels used were as follow: highly significant $p \leq 0.01$, non-significant $p>0.05$, and significant $0.05 \geq p>0.01$.

\section{Results}

ANOVA is used to find significance between wires before and after a deflection. Less than $0.05 p$ value is observed as significant. Table 1 shows esthetic wire roughness before and after a deflection. Fiberreinforced composite wires show 1.93 roughness before deflection and 3.92 after deflection, as the same optiflex shows 1.65 before and 5.01 after deflection. All wires show some degree of roughness after deflection, epoxy-coated NiTi wire shows 3.24 before and 6.57 mean roughness after deflection, rhodium-coated NiTi wires shows 2.01 mean roughness before and 4.83 after a deflection. Fiber-reinforced composite wires showed mild roughness than epoxy-coated $\mathrm{NiTi}$ wire which showed increased roughness. ANOVA shows statistical significance among wire "as received" and post-deflection. Epoxycoated NiTi exhibited significantly increased roughness among other groups "as-received" and after deflection ( $p=0.011)$.

Tukey's honestly significant difference test (HSD) (roughness differentiation among "as-received" and after deflection) showed a significantly increased roughness for epoxy-coated NiTi wire after a deflection.

\section{Discussion}

In orthodontics, the use of esthetic appliances has been increased. The mechanotherapy of tooth movement is dependent on various factors such as plaque accumulation, friction, and corrosion characters. These factors are determined by the characteristics of surface roughness. Deflection is the total energy acquired per distortion in millimeters. In this study, the roughness of esthetic archwires was evaluated before and after load deflection by rugosimeter. Rugosimeter is an instrument used for measuring the surface roughness of the wire. ${ }^{18}$

The roughness depends on the force of two surfaces which determines the quality of tooth movement during orthodontic treatment. ${ }^{19}$ In clinical use of the coated esthetic wires, the loss of coating has been observed over a period of time, hence to observe these changes, a clinical simulation was performed by deflection test. 2,20 The stage of alignment and leveling during orthodontic treatment undergoes large deflection, therefore, a 0.018" wire was chosen in this study.

Epoxy resin-coated wires are a combination of epoxide and synthetic resin, achieved by electrostatic coating. The wire surface is air sprayed with epoxy particles as atomized liquid along with the application of high voltage. This enhances the adhesion, dimensional stability, electrical insulation, and chemical resistance, but the mechanical properties are altered by an increase in the thickness of the epoxy coating. ${ }^{21}$

Optiflex is a modified optical fiber made up of silicon dioxide, silicon resin, and stain-resistant nylon. The mechanical advantage of the optiplex is the flexural modulus, but the fracturing of the core in optiflex on the application of metal ligatures and a sharp instrument is a limitation. ${ }^{22}$

A rhodium-coated archwire is made up of ion implantation of rhodium over sentalloy wire. This increases the shimmering and

Table 1: Esthetic archwire roughness before and after the deflection

\begin{tabular}{|c|c|c|c|c|c|c|c|c|}
\hline \multirow[b]{3}{*}{ S. no. } & \multirow[b]{3}{*}{$\begin{array}{l}\text { Esthetic coating } \\
\text { wire }\end{array}$} & \multicolumn{6}{|c|}{ Roughness } & \multirow[b]{3}{*}{$p$ value } \\
\hline & & \multicolumn{3}{|c|}{ As received } & \multicolumn{3}{|c|}{ After deflection } & \\
\hline & & Mean & $S D$ & $\begin{array}{l}\text { Intergroup } \\
\text { comparison }\end{array}$ & Mean & $S D$ & $\begin{array}{l}\text { Intergroup } \\
\text { comparison }\end{array}$ & \\
\hline 1 & $\begin{array}{l}\text { Fiber-reinforced } \\
\text { composite wires }\end{array}$ & 1.93 & $12.39^{\mathrm{a}}$ & A & 3.92 & $24.38^{b}$ & A & 0.002 \\
\hline 2 & Optiflex wires & 1.65 & $31.05^{\mathrm{b}}$ & B & 5.01 & $36.19^{c}$ & A & 0.231 \\
\hline 3 & $\begin{array}{l}\text { Epoxy-coated } \\
\text { NiTi wires }\end{array}$ & 3.24 & $11.46^{\mathrm{a}}$ & C & 6.57 & $22.36^{\mathrm{b}}$ & C & 0.011 \\
\hline 4 & $\begin{array}{l}\text { Rhodium-coated } \\
\text { NiTi wires }\end{array}$ & 2.01 & $53.84^{\mathrm{a}}$ & $\mathrm{D}$ & 4.83 & $14.39^{b}$ & $\mathrm{D}$ & 0.042 \\
\hline
\end{tabular}

A statistically significant difference $(p=0.05)$ between different time periods in each group is indicated by different letters a, $\mathrm{b}, \mathrm{c}$ in the same line A statistically significant difference $(p=0.05)$ between different time periods in each group is indicated by different letters $A, B, C, D$ in the same column 
surface finish of the metals. The disadvantage of this wire is surface corrosion elicited in stress deflection. ${ }^{23}$

The coatings on the orthodontic wire reduce the surface irregularity and act as a lubricant facilitating the sliding of wire over the bracket. ${ }^{24}$ In earlier research, it has been stated that the roughness is increased on esthetic coatings. ${ }^{25}$ This was verified in this study, that the roughness of epoxy-coated archwires, was significantly higher initially than the other groups. Epoxy-coated archwires showed the highest roughness value post-deflection. The porosity is greater in the epoxy-coated archwires, hence there is increased roughness of the wire, this has also been stated by Kim et al. ${ }^{26}$ The stress concentration locations may function as porosity, leading to the fracture of the coatings under deflection. Moreover, future clinical research is required to understand the outcome of orthodontic treatment requiring longer treatment time, considering the biologic complexity exerted in the movement of the tooth.

The rhodium-coated archwires are called white metals, were shown to be rougher when compared with the parylene polymercoated archwires, and sentalloy non-coated wires, this has been stated by lijima et al. ${ }^{27}$ D'Anto et al. evaluated orthodontic wires microscopically without and with esthetic coating on b-titanium (b-Ti), nickel-titanium (NiTi), and stainless-steel (SS) alloys, and found that implantation of rhodium ions increases sliding and roughness of esthetic wires. ${ }^{25}$ In artificial saliva, deterioration of $\mathrm{NiTi}$ to deflection stress has been proved in areas under tension. ${ }^{23}$ After deflection, the roughness of the wire increases due to corrosion of the surface of the wires. The reduction of flexibility, improving the surface characteristics and increasing hardness is enhanced by the implantation of ions. ${ }^{28}$ However, periodic ion implantation must be done to reduce maximum friction. ${ }^{29}$

Fiber-reinforced polymer composite archwire showed decreased roughness when compared with other esthetic archwires. This is congruent with the previous study conducted by Inami et al. ${ }^{16}$ The disproportion in roughness is associated with the manufacturer, technique of manufacturing, and the surface of the material. ${ }^{14,15,30,31}$

A limitation of the study was the difficulty in extrapolating the values for roughness determined in vitro to an in vivo situation. This was due to the difficulty of reproducing oral conditions such as muscular and occlusal forces, and tooth movement through bone which may affect the binding of the archwire to the bracket.

\section{Conclusion}

The method of coating the wires influences the orthodontic wire roughness. The roughness increases on esthetic wire under deflection. Epoxy-coated wires showed significantly increased roughness in comparison with other esthetic archwires. Future studies are necessary to evaluate other considerations that convict the loss of the coatings over the archwires. Flaying of esthetic coating must be elucidated in clinical use with advanced research in the future.

\section{References}

1. Imai T, Yamagata $S$, Watari $F$, et al. Temperature-dependence of the mechanical properties of FRP orthodontic wire. Dent Mater J 1999;18(2):167-175. DOI: 10.4012/dmj.18.167.

2. Elayyan F, Silikas N, Bearn D. Ex vivo surface and mechanical properties of coated orthodontic archwires. Eur J Orthod 2008;30(6):661-667. DOI: $10.1093 /$ ejo/cjn057.
3. Talass MF. Optiflex arch wire treatment of a skeletal class III open bite. J Clin Orthod 1992;26:25-252.

4. Watari F, Yamagata $\mathrm{S}$, Imai T, et al. The fabrication and properties of aesthetic FRP wires for use in orthodontics. J Mater Sci 1998;33(23):5661-5664. DOI: 10.1023/A:1004484703341.

5. Huang ZM, Gopal R, Fujihara K, et al. Fabrication of a new composite orthodontic archwire and validation by a bridging micromechanics model. Biomaterials 2003;24(17):2941-2953. DOI: 10.1016/S01429612(03)00093-0.

6. Chng CK, Foong K, Gandedkar NH, et al. A new esthetic fiberreinforced polymer composite resin archwire: a comparative atomic force microscope (AFM) and field-emission scanning electron microscope (FESEM) study. Prog Orthod 2014;15(1):39. DOI: 10.1186/ s40510-014-0039-8.

7. Chng CK, Foong K, Gandedkar N, et al. A study of a novel aesthetic archwire on its frictional properties and its applications to orthodontics. APOS Trends Orthod 2014;4(1):16-20. DOI: 10.4103/2321-1407.125745.

8. Kerosuo HM, Dahl JE. Adverse patient reactions during orthodontic treatment with fixed appliances. Am J Orthod Dentofacial Orthop 2007;132(6):789-795. DOI: 10.1016/j.ajodo.2007.01.022.

9. Garoushi S, Lassila L, Vallittu P. Fibre-reinforced composite in clinical dentistry. Chin J Dent Res 2008;11:101-108.

10. Turkkahraman H, Sayin MO, Bozkurt FY, et al. Archwire ligation techniques, microbial colonization, and periodontal status in orthodontically treated patients. Angle Orthod 2005;75:231-236.

11. Quirynen $M$. The clinical meaning of the surface roughness and the surface free energy of intra-oral hard substrata on the microbiology of the supra- and subgingival plaque: results of in vitro and in vivo experiments. J Dent 1994;22:S13-S16. DOI: 10.1016/03005712(94)90165-1.

12. Birnie D. Archwires and archwire technology. Excellence in orthodontics lecture course at the royal college of physician. London. 17th ed, 2005. pp. 223-242.

13. Kusy RP, Whitley JQ, Mayhew MJ, et al. The surface roughness of orthodontic arch wires via laser, spectroscopy. Angle Orthod 1988;58:33-45.

14. Bourauel C, Fries T, Drescher D, et al. Surface roughness of orthodontic wires via atomic force microscopy, laser specular reflectance and profilometry. Eur J Orthod 1998;20(1):79-92. DOI: 10.1093/ejo/ 20.1.79.

15. Daems J, Celis JP, Willems G. Morphological characterization of as-received and in vivo orthodontic stainless steel archwires. Eur J Orthod 2009;31(3):260-265. DOI: 10.1093/ejo/cjn104.

16. Inami T, Tanimoto $Y$, Yamaguchi M, et al. Surface topography, hardness, and frictional properties of GFRP for esthetic orthodontic wires. J Biomed Mater Res B Appl Biomater 2016;104(1):88-95. DOI: 10.1002/jbm.b.33372.

17. Huang $\mathrm{HH}$. Variation in corrosion resistance of nickel-titanium arch wires from different manufacturers. Angle Orthodont 2005;75:661665.

18. Mooney M. Rugosimeter. Instrument for measuring surface roughness of calendered sheet rubber. Ind Eng Chem Anal Ed 1945;17(8):514-517. DOI: 10.1021/i560144a017.

19. Hain M, Dhopatkar A, Rock P. The effect of ligation method on friction in sliding mechanics. Am J Orthod Dentofacial Orthop 2003;123(4):416-422. DOI: 10.1067/mod.2003.14.

20. Juvvadi SR, Kailasam V, Padmanabhan S, et al. Physical, mechanical, and flexural properties of 3 orthodontic wires: an in-vitro study. Am J Orthod Dentofacial Orthop 2010;138(5):623-630. DOI: 10.1016/j. ajodo.2009.01.032.

21. Ramadan AA.Removing hepatitis C virus from polytetrafluoroethylenecoated orthodontic archwires and other dental instruments. East Mediterr Health J 2003;9:274-278.

22. Talass MF. Optical fibers as orthodontic archwires: optiflex. J Showa Univ Dent Soc 1995;15:51-58. 
23. Liu IH, Lee TM, Chang CY, et al. Effect of load deflection on corrosion behavior of NiTi wire. J Dent Res 2007;86(6):539-543. DOI: 10.1177/154405910708600610.

24. Clocheret K, Willems G, Carels C, et al. Dynamic frictional behaviour of orthodontic archwires and brackets. Eur J Orthod 2004;26(2):163-170. DOI: 10.1093/ejo/26.2.163.

25. D'Anto V, Rongo R, Ametrano G, et al. Evaluation of surface roughness of orthodontic wires by means of atomic force microscopy. Angle Orthod 2012;82(5):922-928. DOI: 10.2319/100211-620.1.

26. Kim IH, Park HS, Kim YK, et al. Comparative short-term in vitro analysis of mutans streptococci adhesion on esthetic, nickel-titanium, and stainless-steel arch wires. Angle Orthod 2014;84(4):680-686. DOI: 10.2319/061713-456.1.
27. lijima M, Muguruma T, Brantley W, et al. Effect of coating on properties of esthetic orthodontic nickel-titanium wires. Angle Orthod 2012;82(2):319-325. DOI: 10.2319/021511-112.1.

28. Burstone CJ, Farzin-Nia F. Production of low-friction and colored TMA by ion implantation. J Clin Orthod 1995;29:453-461.

29. Doshi UH, Bhad-Patil WA. Static frictional force and surface roughness of various bracket and wire combinations. Am J Orthod Dentofacial Orthop 2011;139(1):74-79. DOI: 10.1016/j.ajodo.2009.02.031.

30. Ryu SH, Lim BS, Kwak EJ, et al. Surface ultrastructure and mechanical properties of three different white-coated NiTi archwires. Scanning 2015;37(6):414-421. DOI: 10.1002/sca.21230.

31. Zegan G, Sodor A, Munteanu C. Surface characteristics of retrieved coated and nickel-titanium orthodontic archwires. Rom J Morphol Embryol 2012;53(4):935-939. 